\title{
Clinical Characteristics of Mineral Bone Disease Among Patients with Chronic Kidney Disease in Southern, Nigeria
}

\author{
Ndu Victor Onyebuchi“, Oko-Jaja Richard I. , Emem-Chioma Pedro, Wokoma Friday \\ Department of Internal Medicine, University of Port Harcourt Teaching Hospital, Port Harcourt, Nigeria \\ Email address: \\ nduvictor5@gmail.com (N. V. Onyebuchi) \\ ${ }^{*}$ Corresponding author \\ To cite this article: \\ Ndu Victor Onyebuchi, Oko-Jaja Richard I., Emem-Chioma Pedro, Wokoma Friday. Clinical Characteristics of Mineral Bone Disease \\ Among Patients with Chronic Kidney Disease in Southern, Nigeria. American Journal of Internal Medicine. \\ Vol. 7, No. 6, 2019, pp. 163-168. doi: 10.11648/j.ajim.20190706.15
}

Received: October 4, 2019; Accepted: October 21, 2019; Published: December 6, 2019

\begin{abstract}
Mineral bone disease (MBD) is a common complication in patients with chronic kidney disease (CKD). The objective of this study is to determine the characteristics of CKD-MBD among adult patients with CKD in South-South, Nigeria. One hundred and fifty consecutive consenting chronic kidney disease patients who fulfilled the inclusion criteria for this study were recruited. Patients had a detailed clinical assessment, biochemical and radiological evaluations for CKD-MBD. Biochemical investigations included serum calcium, phosphate, parathyroid hormone (PTH) and alkaline phosphatase while the radiological investigations included X-ray of the skull, spine, wrist and phalanges. The age range of the patients was 22-80 years, with a mean of $45.1( \pm 11.9)$ years. There were 90 males and 60 females with male to female ratio of 1.5:1. Symptoms suggestive of CKD-MBD in the study population were bone pain and pruritus occuring in $34.9 \%$ and $12.0 \%$ of the CKD-MBD patients. Other symptoms presented by the patients included leg swelling in $126(84 \%)$, frothiness of urine in $123(82 \%)$, vomiting in $109(72.7 \%)$, facial puffiness in $102(68 \%)$, haematuria in $18(12 \%)$ and chest pain in $73(48.7 \%)$ of the patients. The mean values for serum PTH, serum calcium, serum phosphate, alkaline phosphatase and $\mathrm{caxpo}_{4}$ product among the CKDMBD patients were $205.06 \pm 112.6 \mathrm{pg} / \mathrm{ml}, 2.56 \pm 0.73 \mathrm{mmol} / 1,1.63 \pm 0.63 \mathrm{mmol} / 1,109.26 \pm 65.57 \mathrm{IU} / \mathrm{L}$ and $4.07 \pm 1.28 \mathrm{mmol}^{2} / 1^{2}$ respectively. There was hypercalcaemia in $44.6 \%$, hypocalcaemia in $26.0 \%$, hypophosphataemia in $12.0 \%$ and hyperphosphataemia in $29.3 \%$ of the patients. High alkaline phosphatase was observed in $36.0 \%$ while $8.7 \%$ had low alkaline phosphatase. There was high calcium $\mathrm{x}$ phosphate product in $34.0 \%$ of the patients. Radiological features in keeping with CKD-MBD was present in only $6 \%$ of those with CKD-MBD. Hypercalcemia is the major biochemical abnormalilty in patients with CKD-MBD in our environment.
\end{abstract}

Keywords: CKD, MBD, Kidney Function, Calcium

\section{Introduction}

Chronic kidney disease is a leading cause of morbidity and mortality in the world $[1,2]$. It is an underrated cause of poverty and it hampers economic growth of many countries [3]. Eighty percent of chronic kidney disease deaths occur in low and middle-income countries [3]. It is now recognized as a global public health problem, and its prevalence has increased recently in Sub-Saharan Africa [4-5]. While the disease magnitude have been better characterized in developed countries, increasing evidence shows that developing countries bear the greater burden. Chronic kidney disease and to a greater extent, end-stage renal disease contribute substantially to the burden of illness, disability and premature death across sex, age, race, socio-economic and geographic boundaries [6].

Chronic kidney disease is associated with widespread complications and disorders in mineral and bone metabolism are common complications and important causes of morbidity and decreased quality of life [7]. These can develop in the early stages of renal disease and may even begin several years before the symptoms and radiological changes appear in the adult [8]. Increasing evidence suggest that these changes are associated with changes in arterial compliance, cardiovascular calcification, bone disorders and 
all cause cardiovascular mortality [9-13].

These disorders have previously been termed renal osteodystrophy but recent findings show that the abnormalities in renal osteodystrophy are diverse and include extra-skeletal manifestations. The term chronic kidney disease-mineral and bone disorder (CKD-MBD) was coined by Kidney Disease Improving Global Outcome (KDIGO) conference group in Madrid, Spain in the year 2005 [14-16] This is defined as a systemic disorder of mineral and bone metabolism due to CKD manifested by one or a combination of any of the following: Abnormalities of calcium, phosphorus, Parathyroid hormone $(\mathrm{PTH})$, or vitamin D metabolism, Abnormalities of bone turnover, mineralization, volume, linear growth or strength, Vascular or other soft tissue calcification [17]. In Africa, studies of CKD-MBD are sparse partly due to limitations in laboratory facilities. There are however few studies on components of CKD-MBD such as secondary hyperparathyroidism, serum calcium, serum phosphate levels and vitamin D [18]. This paucity of information may be contributing to the diagnostic difficulty and suboptimal management of the condition in our practice environment. This study was carried out to assess the characteristics of mineral bone disease in University of Port Harcourt Teaching Hospital.

\section{Method}

\subsection{Study Area}

This cross-sectional study was conducted in the Department of Internal Medicine, University of Port Harcourt Teaching Hospital (UPTH) Port Harcourt, Rivers State, Nigeria. University of Port Harcourt Teaching Hospital is a tertiary institution with more than 600 in-patient beds located in Port Harcourt, the capital city of Rivers State, Nigeria. The Department of Internal Medicine has 160 beds with average annual renal admission of 220 patients. The hospital serves as a referral center for patients from Rivers, Bayelsa, Abia, Imo, Cross River, Akwa Ibom and Ebonyi States.

\subsection{Sample Selection}

The study was a descriptive, cross-sectional study of 150 consecutive patients with chronic kidney disease who met the inclusion criteria for the study. Chronic kidney disease was defined as eGFR less than $60 \mathrm{mls} / \mathrm{min} / 1.73 \mathrm{~m}^{2}$ for three months or more with concomitant evidence of kidney damage such as urinary abnormalities (proteinuria, haematuria), structural abnormalities (e.g abnormal renal imaging) and genetic disease (e.g autosomal dominant polycystic kidney disease).

Inclusion Criteria

1. Adults aged 18 years and above.

2. Chronic kidney disease patients who grant informed consent.

3. Chronic kidney disease patients in stages 3-5.

Exclusion Criteria

1. Acute or chronic bone disorders including metastatic

\section{bone disease.}

2. Patients on calcium and vitamin D therapy, or any other drug that may interfere with calcium, phosphate and vitamin D metabolism.

3. Patients who have had renal transplant.

4. Patients with chronic liver disease or other significant organ dysfunction.

5. Patients on long-term steroids.

6. Post-menopausal women.

\subsection{Biochemical Investigations}

Serum creatinine, albumin, calcium, phosphate (PO4), TAP, hemoglobin, uric acid, and urinary protein excretion were measured using standard laboratory techniques. Plasma intact parathormone (iPTH) was measured using the solid phase, two-site chemiluminescent enzyme-labeled immunometric assay (Immulite/Immulite 1000). Plasma 25$\mathrm{OH}$ vitamin D (25-vitD) assay was done using the equilibrium radioimmunometric assay (DiaSorin I125 RIA Kit). Radiological survey of bone was done with lateral Xray of skull, dorsolumbar spine and abdomen, as well as anteroposterior views of pelvis and both wrists including hands. We looked specifically for changes of hyperparathyroidism, osteomalacia, osteoporosis, fracture, as well as soft tissue and vascular calcification.

\subsection{Data Analysis}

Data obtained were analyzed using a commercially available statistical data management soft ware-Statistical package for social sciences package 21. Results were presented as mean \pm standard deviation for continuous variables and percentages for categorical variables. Graphs and tables were also used to illustrate results where appropriate. Continuous variables were compared by the students't-test and categorical parameters were compared with the chi-square test and two tailed fisher's exact test as appropriate. A p-value of less than 0.05 was considered statistically significant.

\section{Results}

The study consisted of 90 males $(60 \%)$ and 60 females $(40 \%)$ with male to female ratio of $1.5: 1$. The age range of the patients was $22-80$ years with mean age of $45.1 \pm 11.9$ years. The age and sex distribution of the patients are shown in Table 1.

Table 1. Demographic distribution of Study Subjects.

\begin{tabular}{llll}
\hline Age (years) & $\begin{array}{l}\text { Frequency } \\
\mathbf{n = 1 5 0}(\mathbf{\%})\end{array}$ & Male n=90 (\%) & Female n= 60 (\%) \\
\hline$\leq 30$ & $16(10.7)$ & $9(6)$ & $7(4.7)$ \\
$31-40$ & $40(26.7)$ & $24(16)$ & $16(10.6)$ \\
$41-50$ & $50(33.3)$ & $18(12)$ & $32(21.3)$ \\
$51-60$ & $26(17.3)$ & $22(14.6)$ & $4(2.7)$ \\
$>60$ & $18(12.0)$ & $17(11.4)$ & $1(0.7)$ \\
Total & $150(100)$ & $90(60)$ & $60(40)$ \\
\hline
\end{tabular}

Table 2 shows the clinical features suggestive of CKD- 
MBD in this study were bone pains and pruritus observed in $55(36.7 \%)$ and $20(13.3 \%)$ of the study population. Other clinical features presented by the CKD patients included leg swelling occuring in $126(84 \%)$ of the patients, frothiness of urine in $123(82 \%)$, vomiting in $109(72.7 \%)$, facial puffiness in $102(68 \%)$, haematuria in $18(12 \%)$, chest pain in 73 (48.7\%) of the patients, pallor in 135 (90\%), oedema in 125
$(83 \%)$ and bone tenderness in $55(36.7 \%)$ of the patients. Though bone pain was the most common clinical symptom suggestive of CKD-MBD among the study population, there was no statistical significant difference observed when compared among CKD-MBD and non CKD-MBD patients $(\mathrm{p}=0.63)$.

Table 2. Clinical symptoms among CKD-MBD and NON-CKD-MBD.

\begin{tabular}{lllll}
\hline Symptoms & CKD-MBD n=83 (\%) & No CKD- MBD n=67 (\%) & Chi-Square & p-value \\
\hline Common complaints & & & & 0.63 \\
Bone pain & $29(34.9)$ & $26(38.8)$ & 0.24 & 0.61 \\
Pruritus & $10(12.0)$ & $10(14.9)$ & 0.27 & 0.17 \\
Nausea and vomiting & $64(77.1)$ & $45(67.2)$ & 1.85 & 0.14 \\
Leg swelling & $73(88.0)$ & $53(79.1)$ & 2.16 & 0.11 \\
Facial puffiness & $61(73.5)$ & $41(61.2)$ & 2.58 & 0.98 \\
Frothiness of urine & $68(81.9)$ & $55(82.1)$ & 0.001 & 0.14 \\
Haematuria & $7(8.4)$ & $31(16.4)$ & 2.24 & 0.60 \\
Chest pain & $42(50.6)$ & $56(83.6)$ & & 0.28 \\
Pattern of symptoms & $76(91.6)$ & $11(16.4)$ & 3.02 & 0.08 \\
Combined symptoms & $7(8.4)$ & &
\end{tabular}

Table 3 shows the distribution and occurrence of pallor, oedema and bone tenderness amons the CKD-MDB and non-CKD MDB subjects. Table 4 shows the comparison of biophysical parameters among CKD-MBD and non-CKD-MBD.

Table 3. Comparison of Clinical Signs among CKD-MBD and non-CKD-MBD.

\begin{tabular}{|c|c|c|c|c|}
\hline Clinical signs & CKD-MBD $n=83(\%)$ & No CKD-MBD $n=67(\%)$ & Chi-square & p-value \\
\hline Pallor & $74(89.2)$ & $61(91.0)$ & 0.147 & 0.702 \\
\hline Oedema & $68(81.9)$ & $57(85.1)$ & 0.624 & 0.607 \\
\hline Bone tenderness & $25(30.1)$ & $30(44.2)$ & 3.429 & 0.064 \\
\hline
\end{tabular}

Table 4. Comparison of Biophysical Parameters among CKD-MBD and non-CKD-MBD.

\begin{tabular}{|c|c|c|c|c|c|}
\hline Variables & CKD-MBD $n=83$ Mean \pm SD & No CKD-MBD n-67 Mean \pm SD & t-test & p-value & $95 \%$ \\
\hline $\operatorname{BMI}\left(\mathrm{kg} / \mathrm{m}^{2}\right)$ & $26.60 \pm 7.36$ & $27.20 \pm 5.60$ & -0.558 & 0.578 & -2.76 to 1.54 \\
\hline Systolic BP (mmHg) & $151.19 \pm 23.7$ & $149.34 \pm 25.90$ & 0.456 & 0.649 & -6.17 to 9.87 \\
\hline Diastolic BP (mmHg) & $92.65 \pm 11.16$ & $90.00 \pm 13.3$ & 1.325 & 0.187 & -1.30 to 6.61 \\
\hline
\end{tabular}

BP (blood pressure), BMI (body mass index).

Tables 5, 6 and 7 shows the comparisons of laboratory findings of biochemical tests between CKD-MBD and non-CKDMBD and dialysis \& non-dialysis patients.

Table 5. Comparison of Laboratory Parameters among CKD-MBD and non-CKD-MBD.

\begin{tabular}{|c|c|c|c|c|c|}
\hline Laboratory parameters & CKD-MBD $n=83$ Mean \pm SD & No CKD-MBD $n=67$ Mean \pm SD & t-test & p-value & $95 \% \mathrm{CI}$ \\
\hline Urine protein $(\mathrm{g} / \mathrm{l})$ & $1.43 \pm 1.13$ & $1.40 \pm 1.01$ & 0.216 & 0.829 & -0.31 to 0.39 \\
\hline PTH & $205.06 \pm 112.6$ & $123.08 \pm 120.99$ & -0.37 & 0.71 & -66.52 to 45.58 \\
\hline Urea $(\mathrm{mmol} / \mathrm{L})$ & $23.53 \pm 11.08$ & $21.43 \pm 12.44$ & 1.091 & 0.277 & -1.70 to 5.90 \\
\hline Creatinine $(\mu \mathrm{mol} / \mathrm{l})$ & $866.92 \pm 505.76$ & $782.13 \pm 714.38$ & 0.849 & 0.397 & -112.45 to 282.02 \\
\hline Calcium (mmol/l) & $2.56 \pm 0.73$ & $2.32 \pm 0.46$ & 2.279 & $0.024 *$ & 0.03 to 044 \\
\hline Phosphate (mmol/l) & $1.63 \pm 0.46$ & $1.54 \pm 0.57$ & 1.010 & 0.314 & -0.08 to 0.25 \\
\hline Sodium $(\mathrm{mmol} / \mathrm{l})$ & $131.07 \pm 26.8$ & $132.27 \pm 24.33$ & -0.285 & 0.776 & -9.57 to 7.16 \\
\hline $\mathrm{HCO}_{3}(\mathrm{mmol} / \mathrm{L})$ & $19.81 \pm 4.36$ & $20.05 \pm 5.03$ & -0.312 & 0.756 & -1.76 to 1.28 \\
\hline Serum albumin $(g / L)$ & $30.89 \pm 10.03$ & $31.67 \pm 9.90$ & -0.474 & 0.636 & -4.01 to 2.46 \\
\hline Total protein $(\mathrm{g} / \mathrm{l})$ & $65.01 \pm 0.36$ & $69.68 \pm 8.96$ & 2.954 & $0.004 *$ & 1.54 to 7.78 \\
\hline Haemoglobin (g/dl) & $8.34 \pm 2.01$ & $9.00 \pm 2.11$ & -1.946 & 0.054 & -1.33 to 0.01 \\
\hline $\operatorname{ALP}(I U / L)$ & $109.26 \pm 65.57$ & $108.13 \pm 51.84$ & 0.115 & 0.909 & 18.29 to 20.55 \\
\hline ALT (IU/L) & $18.93 \pm 12.09$ & $16.42 \pm 8.88$ & 1.418 & 0.158 & 0.99 to 6.01 \\
\hline AST (IU/L) & $21.94 \pm 14.01$ & $20.31 \pm 11.74$ & 0.759 & 0.449 & -2.61 to 5.86 \\
\hline $\mathrm{HbAIC}$ & $5.94 \pm 1.15$ & $5.70 \pm 0.82$ & -1.470 & 0.144 & -0.55 to 0.08 \\
\hline $\mathrm{TG}(\mathrm{mmol} / \mathrm{l})$ & $1.91 \pm 2.42$ & $2.42 \pm 0.72$ & 0.684 & 0.495 & -0.40 to 0.82 \\
\hline $\mathrm{HDL}(\mathrm{mmol} / \mathrm{L})$ & $1.14 \pm 0.62$ & $0.95 \pm 0.60$ & 1.879 & 0.062 & 0.01 to 0.39 \\
\hline
\end{tabular}




\begin{tabular}{llllll}
\hline Laboratory parameters & CKD-MBD $\mathbf{n}=\mathbf{8 3}$ Mean \pm SD & No CKD-MBD $\mathbf{n}=\mathbf{6 7}$ Mean \pm SD & t-test & p-value & $\mathbf{9 5 \%}$ CI \\
\hline $\mathrm{TC}(\mathrm{mmol} / \mathrm{l})$ & $5.45 \pm 2.52$ & $4.99 \pm 1.81$ & 1.258 & 0.210 & -0.26 to 1.19 \\
$\mathrm{LDL}(\mathrm{mmol} / \mathrm{L})$ & $3.50 \pm 2.24$ & $3.23 \pm 1.50$ & 0.847 & 0.398 & -0.36 to 0.90 \\
$\mathrm{eGFR}\left(\mathrm{ml} / \mathrm{min} / 1.73 \mathrm{~m}^{2}\right)$ & $9.83 \pm 5.88$ & $17.21 \pm 13.74$ & -4.423 & $0.01^{*}$ & -10.68 to -4.08 \\
$\mathrm{Ca} \times \mathrm{PO}_{4}\left(\mathrm{mmol} / \mathrm{l}^{2}\right)$ & $4.07 \pm 1.28$ & $3.52 \pm 1.37$ & 2.501 & $0.013^{*}$ & 0.11 to 0.97 \\
\hline
\end{tabular}

PTH - Parathyroid hormone, $\mathrm{HCO}_{3}$ - Bicarbonate, ALP Alkaline phosphatatse, ALT - Alanine transaminase, ALT Aspartate traaminase, FBG - Fasting plasma glucose, HbA1C - Glycated haemoglobin, TG - Triglyceride, HDL -
High density lipoprotein, TC -Total cholesterol, LDL - Low density lipoprotein, eGFR - Estimated glomerular filtration rate, $\mathrm{Ca} \times \mathrm{PO}_{4}$-calcium x phosphate product, $\mathrm{CI}$-confidence interval, *statistically significant.

Table 6. Comparison of laboratory parameters among dialysis and non-dialysis CKD-MBD patients.

\begin{tabular}{|c|c|c|c|c|c|}
\hline Laboratory Findings & On dialysis $n=\mathbf{5 7}$ mean \pm SD & Non dialysis $n=26$ mean \pm SD & t-test & p-value & $95 \%$ CI \\
\hline PTH $(\mathrm{pg} / \mathrm{ml})$ & $225.5 \pm 95.40$ & $150.38 \pm 147.81$ & 1.140 & 0.260 & -151.37 to 41.40 \\
\hline Urea $(\mathrm{mmol} / \mathrm{L})$ & $25.23 \pm 11.33$ & $19.78 \pm 9.70$ & 2.120 & $0.04 *$ & 0.32 to 10.56 \\
\hline Creatinine $(\mu \mathrm{mol} / \mathrm{l})$ & $1018.88 \pm 529.25$ & $533.77 \pm 208.58$ & 4.500 & $<0.001^{*}$ & 270.84 to 699.38 \\
\hline Calcium (mmol/l) & $2.65 \pm 0.83$ & $2.37 \pm 0.41$ & 1.640 & 0.11 & -0.06 to 0.62 \\
\hline Sodium $(\mathrm{mmol} / \mathrm{l})$ & $128.13 \pm 31.89$ & $137.50 \pm 5.20$ & -1.48 & 0.140 & -21.93 to 3.19 \\
\hline Potassium (mmol/l) & $5.02 \pm 1.21$ & $5.02 \pm 0.88$ & 0.022 & 0.982 & -0.53 to 0.52 \\
\hline $\mathrm{HCO}_{3}(\mathrm{mmol} / \mathrm{L})$ & $19.09 \pm 4.62$ & $21.38 \pm 3.30$ & -2.281 & $0.025^{*}$ & -4.30 to -0.29 \\
\hline Total protein $(\mathrm{g} / \mathrm{l})$ & $69.37 \pm 9.70$ & $70.35 \pm 7.18$ & -0.458 & 0.648 & -5.21 to 3.26 \\
\hline Haemoglobin (g/dl) & $8.15 \pm 1.96$ & $8.76 \pm 2.09$ & -1.275 & 0.206 & -1.55 to 0.34 \\
\hline $\operatorname{ALP}(I U / L)$ & $109.64 \pm 71.75$ & $108.43 \pm 60.48$ & 0.078 & 0.938 & -29.84 to 32.28 \\
\hline $\operatorname{ALT}(\mathrm{IU} / \mathrm{L})$ & $15.39 \pm 8.81$ & $26.69 \pm 14.62$ & -4.367 & $<0.001^{*}$ & -16.46 to -6.15 \\
\hline AST (IU/L) & $17.89 \pm 9.06$ & $30.88 \pm 18.41$ & -4.333 & $<0.001^{*}$ & -19.01 to -7.04 \\
\hline $\mathrm{FBG}(\mathrm{mmol} / \mathrm{l})$ & $4.82 \pm 0.83$ & $5.55 \pm 1.34$ & -3.023 & $0.003 *$ & -1.20 to -0.25 \\
\hline $\mathrm{HbAIC}$ & $5.72 \pm 0.78$ & $5.66 \pm 0.91$ & 0.306 & 0.760 & -0.33 to 0.45 \\
\hline $\mathrm{TC}(\mathrm{mmol} / \mathrm{l})$ & $5.22 \pm 1.60$ & $5.98 \pm 3.83$ & -1.281 & 0.204 & -1.94 to 0.42 \\
\hline $\mathrm{LDL}(\mathrm{mmol} / \mathrm{L})$ & $3.27 \pm 1.51$ & $3.99 \pm 3.31$ & -1.361 & 0.177 & -1.77 to 0.33 \\
\hline $\mathrm{eGFR}\left(\mathrm{ml} / \mathrm{min} / 1.73 \mathrm{~m}^{2}\right)$ & $7.65 \pm 4.11$ & $14.61 \pm 4.41$ & -5.959 & $<0.001 *$ & -9.28 to -4.63 \\
\hline $\mathrm{Ca} \times \mathrm{PO}_{4}$ product $\left(\mathrm{mmol}^{2} / \mathrm{L}^{2}\right)$ & $4.18 \pm 1.43$ & $3.82 \pm 0.85$ & 1.173 & 0.244 & -0.24 to 0.96 \\
\hline
\end{tabular}

Table 7 shows that 39 (26.0\%) patients had hypocalcemia, hypercalcemia was seen in 67 (44.6\%), hypophosphatemia in $18(12.0 \%)$ and hyperphosphatasemia in $44(29.3 \%)$ patients. Low alkaline phosphatase was observed in $13(8.7 \%)$ patients, high alkaline phosphatase in $54(36.0 \%)$. Calciumphosphate product was high in $51(34.0 \%)$ patients. Table 8 shows the distribution of radiological features among the CKD-MDB subjects and non-CKD-MDB subjects. Pepperpot skull was observed in $1(0.7 \%)$ of the patients, digital subperiosteal erosion in $8(5.3 \%)$, osteopenia in $2(1.3 \%)$ and vascular calcification was seen in $5(3.3 \%)$ of the study population. The kidneys showed increase echogenicity in 150 $(100 \%)$ patients on renal ultrasound scan. In 147 (98\%) patients, the kidney showed poor corticomedullary differentiation. There was no statistical significant difference observed on comparison of radiological features among CKD-MBD and non CKD-MBD patients

Table 7. Comparison of mineral abnormalities among CKD-MBD and non CKD-MBD.

\begin{tabular}{|c|c|c|c|c|}
\hline Variables & CKD-MBD n=83 (\%) & No CKD-MBD n=67 (\%) & Chi-square & p-value \\
\hline \multicolumn{5}{|l|}{ Serum calcium $(\mathrm{mmol} / \mathrm{L})$} \\
\hline Hypocalcaemia & $19(22.9)$ & $20(29.9)$ & \multirow{3}{*}{8.79} & \multirow{3}{*}{$0.042 *$} \\
\hline Normal calcium & $23(27.7)$ & $21(31.3)$ & & \\
\hline Hypercalcemia & $41(49.4)$ & $26(38.8)$ & & \\
\hline \multicolumn{5}{|l|}{ Serum phosphate $(\mathrm{mmol} / \mathrm{L})$} \\
\hline Hypophosphatemia & $6(7.2)$ & $12(17.9)$ & \multirow{3}{*}{4.99} & \multirow{3}{*}{0.08} \\
\hline Normal phosphate & $54(65.1)$ & $34(50.7)$ & & \\
\hline Hyperphosphatemia & $23(27.7)$ & $21(31.3)$ & & \\
\hline \multicolumn{5}{|l|}{ Alkaline phosphatase (IU/L) } \\
\hline Low alkaline phosphatase & $6(7.2)$ & $7(10.4)$ & \multirow{3}{*}{1.87} & \multirow{3}{*}{0.39} \\
\hline Normal alkaline phosphatase & $50(60.2)$ & $33(49.3)$ & & \\
\hline High alkaline phosphatase & $27(32.5)$ & $27(40.3)$ & & \\
\hline \multicolumn{5}{|l|}{$\mathrm{CaxPO}_{4}\left(\mathrm{mmol}^{2} / \mathrm{L}^{2}\right)$} \\
\hline Low & $29(34.9)$ & $40(59.7)$ & \multirow{2}{*}{9.37} & \multirow{2}{*}{$0.01 *$} \\
\hline High & $33(39.8)$ & $18(26.9)$ & & \\
\hline
\end{tabular}


Table 8. Comparison of Radiological Features among CKD-MBD and non-CKD-MBD.

\begin{tabular}{lll}
\hline Variables & CKD-MBD n=83 (\%) & No CKD-MBD n=67 (\%) \\
\hline Chest X-ray & & Fisher's exact p-values \\
Vascular calcification & $2(2.4)$ & $3(4.5)$ \\
Normal findings & $81(97.6)$ & $64(95.5)$ \\
Spine x-ray & & \\
Normal spine & $83(100.0)$ & $67(100.0)$ \\
Skull x-ray & & \\
Pepperpot skull & $1(1.2)$ & $0(0.0)$ \\
Normal finding & $82(98.8)$ & $67(100.0)$ \\
Hand and wrist X-ray & & \\
Sub-periosteal erosion & $2(2.4)$ & $6(9.0)$ \\
Osteopenia & $0(0.0)$ & $2(3.0)$ \\
Normal findings & $81(97.6)$ & $59(88.1)$ \\
Renal scan & & $67(100.0)$ \\
Increase echogenecity & $83(100.0)$ & $0(0.0)$ \\
Good corticomedullary differentiation & $3(3.6)$ & $67(100.0)$ \\
Poor corticomedullary differentiation & $80(96.4)$ & 0.05 \\
\hline
\end{tabular}

\section{Discussion}

The study population was made up of more male than females with male to female ratio of 1.5:1. There was male preponderance in both CKD-MBD and non-CKD-MBD patients, though this difference was not statistically significant. This male preponderance in this study is consistent with the findings of the work done in Benin by Onyemekeihia 18 that reported $58 \%$ of male, and that of Sanusi et al.[19] The males are the breadwinners and by the nature of their lifestyle and occupation they are constantly being exposed to stress and more likely to adopt a western type of diet with consumption of high cholesterol foods, use of alcohol and smoking resulting to increased prevalence of various risk factors of CKD such as hypertension, diabetes and hyperlipidemia, and therefore eventually prone to subsequent complications of CKD including CKD-MBD. Male preponderance may also reflect the fact that females are less likely than male to go to the hospital for cultural and financial reasons rather than a difference in incidence [20].

Hypercalcemia was the most common biochemical abnormality found in this study. This finding is in sharp contrast to the findings in IIe-Ife by Onyemekeihia [18] and that of Sanusi et al [19] in Benin where hypocalcemia and hyperphosphatemia were the most common biochemical abnormalities. Agarwal et al [21] also reported low prevalence of hypercalcemia but high prevalence of hypocalcemia and hyperphosphatemia in their study population. This discrepancy may be attributed to the fact that majority of our patients had adynamic bone disease. Calcium kinetic studies have shown that patients with adynamic bone disease have decrease capacity for buffering of calcium by bone and therefore may be unable to handle an extra calcium load, this may results to hypercalcemia even when exposed to very low calcium.[22] Though majority of our patients had adynamic bone disease but some had severe hyperparathyroidism; long standing severe secondary hyperparathyroidism can lead to hyperplasia of the parathyroid glands with autonomous or tertiary hyperparathyroidism in which hypercalcemia is present [23].

Even though the mean value of calcium in dialysis patients was higher compared to that of non-dialysis patients in this study; there was no statistically significant difference observed, this may show that dialysate calcium used during haemodialysis may have played just little or no role in the aetiology of hypercalcemia observed in this study. Hypercalcemia may result in calcium deposition in the vasculature and myocardium, increased risk of fracture due to impaired remodeling process, and shortening of life expectancy in ESRD population [23]. In order to avoid these complications, the most recent Dialysis Outcome Quality Initiative (DOQI) guidelines suggest that in cases of low turnover bone disease, PTH should be allowed to rise, aiming for increased bone turnover [7, 24].

Bone pain was the most common presenting symptom of CKD-MBD in this study and similar with the findings of Onyemekeiha [18], Sanusi et al [19] and Osuntokun et al. [20] This is due to increased stimulation of specialized pain-sensitive nerve fibers that innervate bone tissues in advanced CKD and other chronic bone diseases. Also increased weight bearing associated with fluid retention in advance CKD aggravates the pain $[25,26]$. The low prevalence of radiological features of CKD-MBD found in this study corroborate that of Onyemekeihia18 in Benin and Odenigbo et al [26] who reported presence of radiological features in $2 \%$ and $3.35 \%$ of their patients respectively. This finding is also consistent with that of an Indian study that reported a very low prevalence of radiological abnormalities in the study patients [21].

It has been shown that more than $50 \%$ of the bone can be lost without any radiological evidence, because only the cortical bone is clearly noted, and important loss of cancellous bone should occur before radiogical features of CKD-MBD can be seen [27]. So, the fact that most CKD patients in our environment do not receive adequate dialysis due to financial constraint and do not live long enough for these changes to occur and be seen on x-ray may have contributed to this low yield of CKD-MBD using X-ray. Indeed, the recent KDIGO guideline did not advocate plain 
$\mathrm{X}$-ray for the evaluation of bone disease in CKD and even recommended restricted use of DEXA for measuring bone mineral density. However, KDIGO guideline recommended use of $\mathrm{x}$-ray for detection of vascular calcification.

\section{Conclusion}

Bone pain was the commonest clinical presentation of CKD-MBD in our study setting occurring in $36.7 \%$ of the patients. Hypercalcemia was the most common mineral abnormality in our study population. Only $6.0 \%$ of those with CKD-MBD had radiological features. The reported characteristics are seemingly common occurrences in patients with CKD-MDB in the local setting.

\section{Author Contributions}

NVO, collected the data and wrote the first draft. ORI, analyzed the data. EPC. and WFS coordinated the literature search and edited the first draft. All authors agreed on the final draft submitted for consideration.

\section{Conflict of Interest Statement}

The authors declare there is no conflict of interest in this publication.

\section{References}

[1] Adelekun T A, Akinsola A. Hypertension induced chronic renal failure: clinical features, management and prognosis. West Afri J Med 1998; 17: 104-108.

[2] Beaglehole R, Yach D. Globalization and the prevention and control of non-communicable disease. The neglected chronic kidney disease of adult. Lancet 2003; 362: 903-8.

[3] Atkins RC. The changing patterns of chronic kidney disease: the need to develop strategies for prevention relevant to different regions and Countries. Kidney Int Suppl 2005; 98: 83-5.

[4] K/DOQI clinical practice guideline for chronic kidney disease: evaluation, classification, stratification. Part IV: Definition and classification of stages of chronic kidney disease. Am J Kidney Dis. 2002; 39: 546-75.

[5] Arogundade F A, Barsoum RS. CKD prevention in subSaharan Africa: a call for government, non-government and community support. Am J Kidney Dis. 2008; 51: 515-23.

[6] Pugsley D, Norris KC, Garcia-Garcia G, Agodoa L. Global approaches for understanding the disproportionate burden of chronic kidney disease. Ethn Dis 2009; 19: 1-2.

[7] National Kidney Foundation. K/DOQI clinical practice guideline for chronic kidney disease: evaluation, classification and stratification. Am J Kid Dis. 2002; 39: 1-226.

[8] Baker LRL. Renal Disease In: Kumar P, Clark M. Clinical medicine, $4^{\text {th }}$ edn. W. B Saunders. Philadephia. 1999; 20: 572-73.

[9] Kadiri S. Towards reducing the impact of chronic kidney disease. African Health 2001; 23: 9-10.
[10] Kadiri S, Arijie A. Temporal variations and metrological factors in hospital admission of chronic renal failure in Southsouth Nigeria. West Afri J Med 1999; 18: 49-51.

[11] EL Nahas M, Bello AK. Chronic Kidney Disease: the global challenge. Lancet 2005; 365: 331-40.

[12] Barsoum RS, Francis MR. Spectrum of glomerulonephritis in Egypt. Saudi J Kidney Dis Transpl. 2000; 11: 421-9.

[13] Barsoum RS. Chronic Kidney disease in the developing world. N Engl J Med. 2009; 354:997-9.

[14] Akinsola W, Odesanmi WO, Oguniyi JO, Ladipo GOA. Diseases causing chronic renal failure in Nigeria: a prospective study of 100 cases. Afri J Med Sc. 1989; 18: 131-5.

[15] Hartmut M, Maria-Claude F. Renal bone disease: an unmet challenge for the nephrologist: Kidney Int. 1990; 38: 193-205.

[16] Palmer SC, Strippoli GF. Interventions for preventing bone disease in kidney transplant recepients: a systemic review of randomized controlled trials. Am J Kidney disease 2005; 45: 638-49.

[17] Moe S, Drueke T. Definition, evaluation and classification of renal osteodystrophy: a position statement from kidney disease improving global outcome. Kidney Int. 2006; 69: 1945-53.

[18] Onyemekeihia R. Renal osteodystrophy in Benin. A dissertation submitted to the National Postgraduate Medical College of Nigeria, faculty of internal medicine. November 2004.

[19] Sanusi AA, Arogundade FA, Oladigbo M. Prevalence and pattern of renal bone disease in end stage renal disease patients in IIe-Ife, Nigeria. West Afri J Med 2010; 29: 75-80.

[20] Osunkotun BO, Odeku EI, Adeloye R. Non-embolic cerebrovascular disease in Nigerians. J neuro. Sci 1969; 19: 361-388.

[21] Agarwal SK. Assessment of renal bone mineral disorder in naïve CKD patients. A single centre prospective study. Indian J Nephrol 2007; 17: 96-100.

[22] Kurz P, Monier Faugere M, Bougna B et al. Evidence for abnormal calcium hemostasis in patients with adynamic bone disease. Kidney Int 1994; 46: 855-861.

[23] London GM, Pannier B, Marchias SJ, Guerin A. Calcification of aortic valve in dialysed patients. J Am Soc Nephrol 2000; 11: 778-783.

[24] Odenigbo CU. The prevalence and radiological markers of ROD in patients with chronic renal failure in Enugu FMCP, National Postgraduate Medical College of Nigeria may 2003.

[25] Harowin P, Lecomte-Houcke M, Flipo RM. Current aspects of osteoarticular pathology in patients undergoing haemodialysis. Study of 80 patients. Laboratory and pathologic analysis. Discussion of the pathologic mechanism. J Rheumatol. 1987; 14: 748-9.

[26] Liach F. Secondary hyperparathyroidism in renal failure: The trade off hypothesis revisited. Am J Kidney Dis 1995; 25 (5): 663-79.

[27] Poznanki AK. Radiological evaluation of bone mineral in children. In favus MJ (ed) primer on Metabolic bone disease and disorders of mineral metabolism. Raven press New York 1993: 115-20. 